\title{
Implementation of lung cancer screening: what are the main issues?
}

\author{
Carlijn M. van der Aalst, Kevin ten Haaf, Harry J. de Koning; for the 4-IN-THE-LUNG-RUN \\ Consortium
}

Department of Public Health, Erasmus MC-University Medical Center Rotterdam, Rotterdam, The Netherlands

Contributions: (I) Conception and design: All authors; (II) Administrative support: None; (III) Provision of study materials or patients: None; (IV) Collection and assembly of data: All authors; (V) Data analysis and interpretation: All authors; (VI) Manuscript writing: All authors; (VII) Final approval of manuscript: All authors.

Correspondence to: Carlijn M. van der Aalst, PhD. Department of Public Health, Erasmus MC-University Medical Center Rotterdam, P.O. Box 2040, 3000 CA Rotterdam, The Netherlands. Email: c.vanderaalst@erasmusmc.nl.

\begin{abstract}
Two large-scale RCTs have shown computed tomography (CT) lung cancer screening to be efficacious in reducing lung cancer mortality (8-24\% in men, 26-59\% in women). However, lung cancer screening implicitly means personalised and risk-based approaches. Health care systems' implementation of personalised screening and prevention is still sparse, and likely to be of variable quality, because of important remaining uncertainties, which have been incompletely addressed or not at all so far. Further optimisation of lung cancer screening programs is expected to reduce harms and maintain or enhance benefit for eligible European citizens, whilst significantly reducing health care costs. Some main uncertainties (e.g., Riskbased eligibility, Risk-based screening intervals, Volume CT screening, Smoking Cessation, Gender and Sex differences, Cost-Effectiveness) are discussed in this review. 4-IN-THE-LUNG-RUN (acronym for: Towards INdividually tailored INvitations, screening INtervals and INtegrated co-morbidity reducing strategies in lung cancer screening) is the first multi-centred implementation trial on volume CT lung cancer screening amongst 24,000 males and females, at high risk for developing lung cancer, across five European countries, started in January 2020. Through providing answers to the remaining questions with this trial, many EU citizens will swiftly benefit from this high-quality screening technology, others will face less harms than previously anticipated, and health care costs will be substantially reduced. Implementing a new cancer screening programme is a major task, with many stakeholders and many possible facilitators but also barriers and obstacle.
\end{abstract}

Keywords: Lung cancer; early detection; screening; computed tomography scanning (CT scanning); implementation

Submitted Aug 27, 2020. Accepted for publication Nov 12, 2020.

doi: $10.21037 /$ tlcr-20-985

View this article at: http://dx.doi.org/10.21037/tlcr-20-985

\section{Introduction}

Lung cancer is the leading cause of cancer-related mortality among both men and women, accounting for $28 \%$ of all cancer deaths in Europe. In 2018, 470,000 people in the European Union (EU) were diagnosed with lung cancer and about 338,000 people died from this disease (1). This is more than all breast, colorectal, and cervical cancer deaths combined. About $70 \%$ of lung cancers are in an advanced stage at time of diagnosis, resulting in 5-year survival rates of approximately $15 \%$ (2).

After refraining from smoking (3), low-dose computed tomography (CT) lung cancer screening is the best prevention method for reducing lung cancer mortality. In 2011, the National Lung Screening Trial (NLST; U.S.) reported a $20 \%$ lung cancer-related mortality reduction 
and a $6.7 \%$ reduction in all-cause mortality after three annual CT screenings (screen arm) compared with chest radiography screening (control arm) for lung cancer in 53,454 subjects at high risk for developing lung cancer after a median follow-up of 6.5 years (4). Consequently, the United States Preventive Services Task Force (USPSTF) recommended to annually screen current or former smokers (who quit smoking $<15$ years prior) aged $55-80$ years with a smoking history of $\geq 30$ pack-year after an independent review and modelling study $(5,6)$. In 2020, the Dutch-Belgian Lung Cancer Screening randomizedcontrolled trial (NELSON), 15,792 participants at high risk for developing lung cancer were randomized (1:1) to undergo four CT lung cancer screening rounds at baseline, year 1, year 3 and year 5.5 or to no screening. The trial results showed a lung cancer mortality reduction between 26\% (men) and 39-61\% (women) at 10-year of follow-up (7). Thus, these two large-scale randomized controlled trials have now provided conclusive evidence that CT lung cancer screening is efficacious in reducing lung cancer mortality in high-risk populations $(4,7)$. Other smaller, unpowered, European trials showed overall (non) significant benefits of lung cancer screening [DANTE: HR 0.99 (95\% CI: 0.69-1.43) (8); DLCST: HR 1.03 (95\% CI: 0.66-1.60) (9); ITALUNG: HR 1.64 (95\% CI: 0.67-4.01) (10); MILD: HR 0.61 (95\% CI: 0.39-0.95) (11); LUSI: HR 0.31 (95\% CI: 0.10-0.96) (12)]. Despite effective tobacco control efforts, U.S. estimates suggest millions of persons will remain eligible for lung cancer screening over the next decades (13). Given past and projected future smoking patterns, also millions of men and women are expected to be eligible for lung cancer screening in Europe in the next decades. CT lung cancer screening is estimated to save tens of thousands of lives in Europe annually, which is likely to be comparable or even more than most other single existing cancer screening programme is presently achieving. However, effective and high-quality implementation of CT lung cancer screening requires important remaining uncertainties to be addressed. Lung cancer screening implicitly means personalised and riskbased approaches, since never smokers or incidental smokers do not encounter substantial risks. However, health care systems' implementation of personalised screening and prevention is still sparse, and likely to be of variable quality and quantity if not addressed systematically in Europe. The aim of this article is to discuss the most important issues related to the widespread implementation of volume CT lung cancer screening.

\section{Requirements for the effective implementation of CT lung cancer screening}

Research shows that adequate organizational, financial, and legal frameworks are prerequisites for the wide-spread implementation of high-quality population cancer screening programmes.

Several crucial phases for a successful implementation of (lung) cancer screening have been identified (14). These phases emphasize the need for an implementation strategy that focus on careful (pre-)planning, piloting, and thereafter a gradual upscaling until a nationwide programme is established (Figure 1) (14). So far, lung cancer screening has been implemented in the U.S. following the recommendations of the USPSTF. However, the low screening uptake and the high number of false-positive results and subsequent follow-up procedures are examples of barriers that impede further implementation in European countries, where lung cancer screening is currently in the (pre)planning phase. Further optimization can reduce the potential harms (false-positives, costs) drastically, while maintaining or even enhancing the benefits associated with lung cancer screening. Some key components that need to be addressed to increase the feasibility of lung cancer screening implementation are described below.

\section{A tailored (self) recruitment strategy}

A major challenge for effectively implementing a lung cancer screening programme is the adequate recruitment and selection of the target population. Other cancer screening programmes primarily focus on selection based on age and sex. However, for lung cancer screening the recent draft evidence review of the USPSTF suggests to invite asymptomatic men and women aged 50-80 years with a long-term smoking history ( $>20$ pack years), who currently smoke or quit smoking in the past 15 years (15). This requires the (self)selection of a specified population from the general population. Important is that this (self) selection is based on an adequate risk assessment instead of inaccurate self-selection (based on for example worry, incorrectly perceived risk and/or knowledge) or case finding to ensure programme quality and cost-effectiveness.

Thereby, recruitment strategies usually tend to use a general method to approach the population in the eligible age-range in which the information materials and invitation are characterised by a one-size-fits-all perspective. This method may seem fair at first sight, since the aim is to 


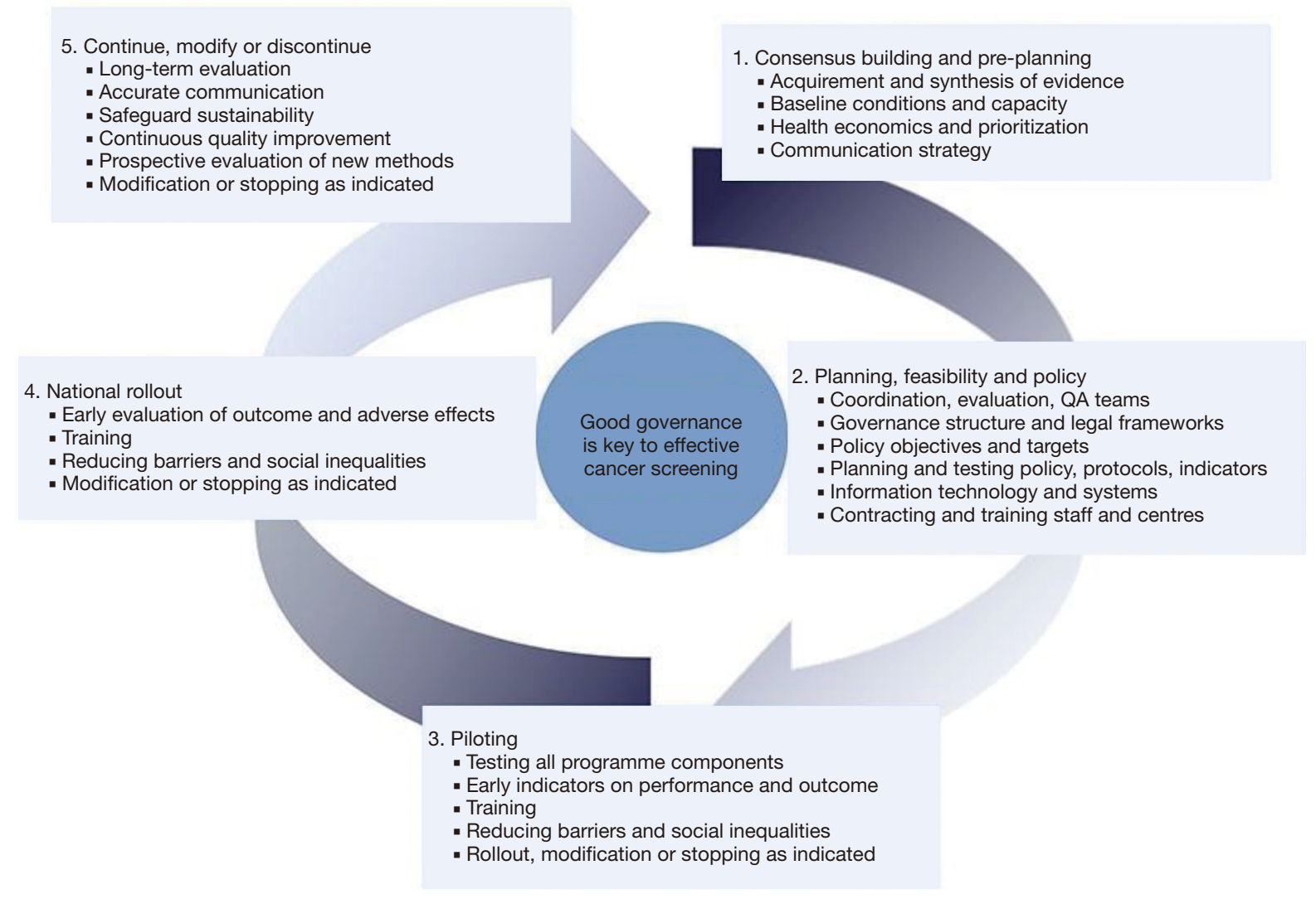

Figure 1 Examples of tasks of organization, evaluation, and governance in different phases of implementation and quality improvement of a cancer screening programme [re-used with permission of ref. (14)].

reach a whole population with acceptable costs, being inclusive rather than exclusive. However, the question is whether this method actually disadvantages those who tend not to participate in healthcare interventions. This method is characterized by a lack of individualization of information, in which one does not consider the differences in information needs and how individuals respond to different methods of invitation. Especially when we consider that those who are expected to benefit most from lung cancer screening are also those who are the least likely to participate, more tailored information is urgently needed. Previous results showed low participation rates among individuals in the more deprived socioeconomic groups (SES), although lung cancer risk is elevated in these groups (4,16-19). Thereby, racial differences in lung cancer incidence, lung cancer screening eligibility, health care access and health outcomes also suggest that more personalized screening programmes are needed to reduce health inequality. Interestingly is that the factors relating to eligibility for lung cancer screening differ from the factors associated with (intended) lung cancer screening uptake, which is relevant for the communication with the target population. Factors associated with (intended) lung cancer screening uptake are for example the smoking status, the perceived (lung cancer) risk/worry/stigma, knowledge, nicotine dependency, the perceived benefits of the detection and treatment of early stage lung cancer. Practical aspects of lung cancer screening as the distance to the screening site and referrals from clinicians turned out to be important too (20-25).

The UK Lung Screen Uptake Trial unfortunately did not find an improved uptake by using a targeted invitation strategy in the hard-to-reach, high-risk population, although an uptake of about $52-53 \%$ was acceptable (25). This emphasizes the difficulty to increase informed uptake amongst those who might benefit most. When there is an intention for screening participation, eligibles could be more easily been asked to complete the risk assessment, 
and if eligible, informed most optimally about (non-) participation. The SUMMIT trial showed that more intensive recruitment method might be workable (26). Important is the lack of evidence about (I) the information needs per subcategory of the general (high-risk) population, (II) the potential teachable moments to contact/invite potential eligibles and (III) preferences regarding the media of recruitment materials (letter, brochure, online information, interactive website, call centre, health care provider). Fortunately, information may derive from other screening programmes that apply self-recruitment strategies, like HPV self-sampling for cervical cancer screening, or faecal immunochemical testing (FIT) at home for colorectal cancer screening. Crucial is the availability of registries such as population registries, GP registries, medical records, or health care registrations to reach the whole potential eligible population in a (cost)effective way.

More research and sharing of experiences are required to develop adequate recruitment approaches that are useful for the large-scale implementation of lung cancer screening.

\section{Risk-based eligibility}

Risk-based selection and screening of individuals is essential to ensure the efficiency and cost-effectiveness of lung cancer screening (27-31). For lung cancer screening, the smoking history is an important risk factor used for the selection, which is different from other cancer screening programmes, where selection mainly relies on age and gender only. This requires adequate tailored information to increase the awareness about the role of (prior) smoking in developing lung cancer, their potential risk, the potential for lung cancer screening and their expected eligibility.

A quite specific issue in applying a tailored approach is how to deal with low-risk former smokers and never smokers for which the harms of screening and follow-up may outweigh the benefits, but who experience distress or anxiety for developing lung cancer. Questions remain on how such individuals can be informed adequately to prevent screening of the low-risk population. On the other hand, lung cancer can still develop in those with lung cancer risks deemed to be too low to be eligible for participating in population screening programmes. Furthermore, formerly ineligible individuals can become eligible if their personal risk factors cause them to accumulate further risk. Therefore, adequate information provision is essential to prevent patient delay in health seeking behaviour, as well as to optimize future lung cancer screening uptake.
Most eligibility criteria for CT lung cancer screening in the U.S. have been based on the results of the NLST and modelling studies $(4,5,32)$. Thereafter, risk models were developed in which a few questions related to demographic characteristics (e.g., age, gender, level of education, ethnicity), smoking related characteristics (e.g., smoking status, number of cigarettes smoked per day, the duration of smoking, the duration of smoking abstinence), and health related characteristics (e.g., BMI, personal history of lung cancer and/or COPD, family history of lung cancer) are applied to predict lung cancer screening eligibility (Table 1). Tammemägi and colleagues developed a more elaborate risk questionnaire and were one of the first to assess the relative benefits of using a risk-prediction model for eligibility. They showed proportionally increasing favourable harmbenefit ratios by increasing risk levels (high risk individuals) and no benefit in the NLST for individuals with a 6-year lung cancer risk below $1.5 \%$ (low risk individuals) (33). Applying the Prostate, Lung, Colorectal, and Ovarian model $\left(\mathrm{PLCO}_{\mathrm{m} 2012}\right)$ with a $1.83 \%$ risk threshold led to improved selection of individuals in the control arm of the PLCO compared to the USPSTF criteria, with regards to both sensitivity (USPSTF criteria: $75.3 \%, \mathrm{PLCO}_{\mathrm{m} 2012}$ : $82.7 \%$ ) and specificity (USPSTF criteria: $61.6 \%$, $\mathrm{PLCO}_{\mathrm{m} 2012}: 61.7 \%$ ) (28). Furthermore, microsimulation modelling suggests that applying the PLCO $\mathrm{m}_{\mathrm{m} 2012}$ risk model with a $1.83 \%$ risk threshold yields a similar number of life-year gained as the USPSTF criteria, but requires 6\% less CT screens (34). Furthermore, racial disparaties were found in using the USPSTF criteria, in which some highrisk individuals were less likely to be eligible for lung cancer screening, although the higher lung cancer incidence and lower survival rates in the racial group $(35,36)$. Recent evaluation in 883 ever smokers showed that the use of the $\mathrm{PLCO}_{\mathrm{m} 2012}$ was more preferable over the USPSTF criteria to select those eligible for lung cancer screening in African Americans. Thereby, greater sensitivity was found in the Hispanic and Asian American population. The use of $\mathrm{PLCO}_{\mathrm{m} 2012}$ may be helpful in reducing racial inequalities in lung cancer screening and health outcomes (37).

Thereby, it is good to realise that risk-based strategies are more likely to recruit older individuals and other groups with diminished life-expectancies (34,38). More research is needed to identify the optimal thresholds for risk-based selection of lung cancer screening eligibles.

Risk-prediction models have since also been used to identify eligible individuals in various trials and implementation pilots. The UK Lung Screen (UKLS) trial 
Table 1 Potential variables for risk-based selection of eligibles for lung cancer screening that can be measured through self-completion

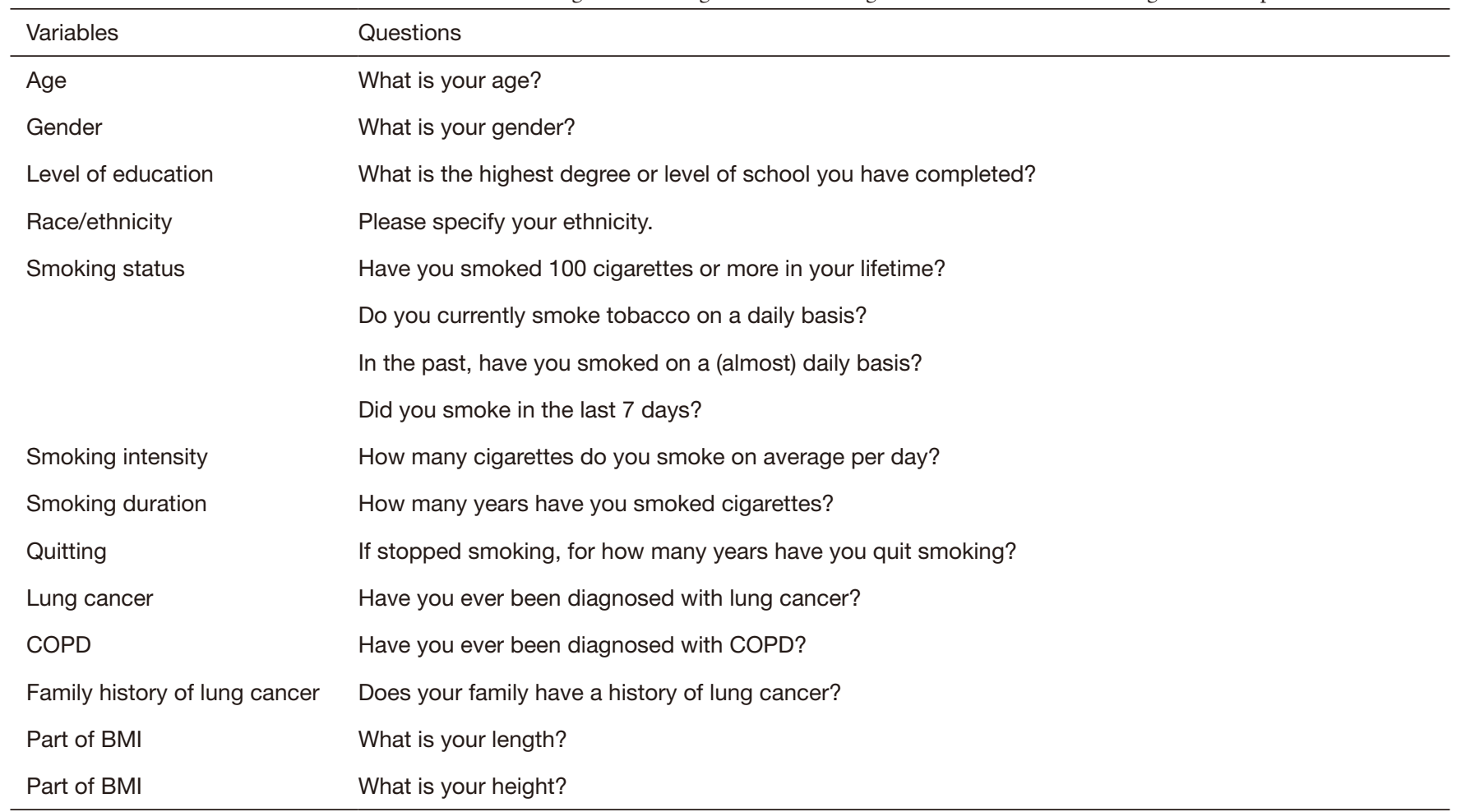

used their Liverpool Lung Project $\left(\operatorname{LLP}_{\mathrm{v} 2}\right)$ risk model to identify those eligible for lung cancer screening, where 42 (2.1\%) participants were diagnosed with lung cancer (17). The Pan-Canadian Early Detection of Lung Cancer (PanCan) study showed that a precursor to the $\mathrm{PLCO}_{\mathrm{m} 2012}$ was effective in identifying individuals with early stage lung cancer (39). The International Lung Screening Trial started recently to evaluate the comparative accuracy and effectiveness of risk-based selection using the USPSTF eligibility criteria as compared to the PLCO $_{\mathrm{M} 2012}$ model (6-year risk $\geq 1.51 \%$ ) (40). The Lung Health Check, which is a community-based lung cancer screening programme, with a risk-based selection based on lung cancer risk models $\left(\mathrm{PLCO}_{\mathrm{m} 2012}\right.$ 6-year risk $\geq 1.51 \%$ and $\mathrm{LLP}_{\mathrm{v} 2} \geq 2.5 \%$ ) or the NLST-criteria in ever smokers (aged 55-74) from deprived areas showed significant variation in selecting those eligible for lung cancer screening between these different methods (41).

Furthermore, risks for developing lung cancer will vary per person over time, due to changes in risk factors as smoking history, but also age. Consequently, ineligibles might become eligible for lung cancer screening or vice versa after some time. Therefore, regularly risk assessment for those who are close to the eligibility threshold should be considered to ensure that only eligibles are in the screening programme. With only few questions, eligibility might be calculated easily (Table 1).

\section{Risk-based screening intervals}

Another important question is whether lung cancer screening intervals can be stratified by risk to further improve the harms-benefits ratio. Current trial results and modelling favour annual screening, but risk-stratification by CT result and/or other outcomes may substantially reduce harms by reducing the screens needed (false positives and work-up procedures, overdiagnosis, radiation induced cancers), and costs. However, the natural history of this disease makes it crucial to get hard trial evidence before increasing the screening interval by risk-stratification.

Based on NLST data, and modelling the natural history of lung cancer, annual screens are considered the standard in CT lung cancer screening. However, NLST participants with a negative baseline CT-result (i.e., no abnormality, including detected nodules $<4 \mathrm{~mm}$ in diameter) had a subsequent lung cancer detection rate of $0.34 \%$ compared 


\begin{tabular}{|c|c|c|c|}
\hline \multicolumn{4}{|c|}{ Personalized risk-based CT lung cancer screening } \\
\hline Individually tailored invitations & Individualized risk assessment & Individualized screening Intervals & $\begin{array}{c}\text { Integrated co-morbidity reducing } \\
\text { strategies }\end{array}$ \\
\hline $\begin{array}{l}\text { - Define target population for risk } \\
\text { assessment } \\
\text { * Based on main risk factors as age, } \\
\text { smoking history } \\
\text { - Define effective tailored recruitment } \\
\text { strategies } \\
\text { - Define gender differences }\end{array}$ & $\begin{array}{l}\text { - Define risk threshold } \\
\text { * Above risk threshold: } \\
\text { - Invitation for screening } \\
\text { * Below threshold: } \\
\text { - Information about expected harms- } \\
\text { benefits ratio } \\
\text { - Information about regularly risk } \\
\text { assessment } \\
\text { - Define re-assessment strategy } \\
\text { - Define criteria for exit strategy } \\
\text { - Define gender differences }\end{array}$ & $\begin{array}{l}\text { - Define risk-based screening intervals } \\
\text { - Define gender differences }\end{array}$ & $\begin{array}{l}\text { - Health promotion using personalized } \\
\text { information from the CT scan about } \\
\text { * Lung cancer } \\
\text { * Coronary heart disease } \\
{ }^{*} \text { COPD } \\
\text { - Optimize use of teachable moments } \\
\text { - Prevent false reassurance } \\
\text { - Define gender differences }\end{array}$ \\
\hline
\end{tabular}

Figure 2 Challenges in the implementation of lung cancer screening.

Possible barriers

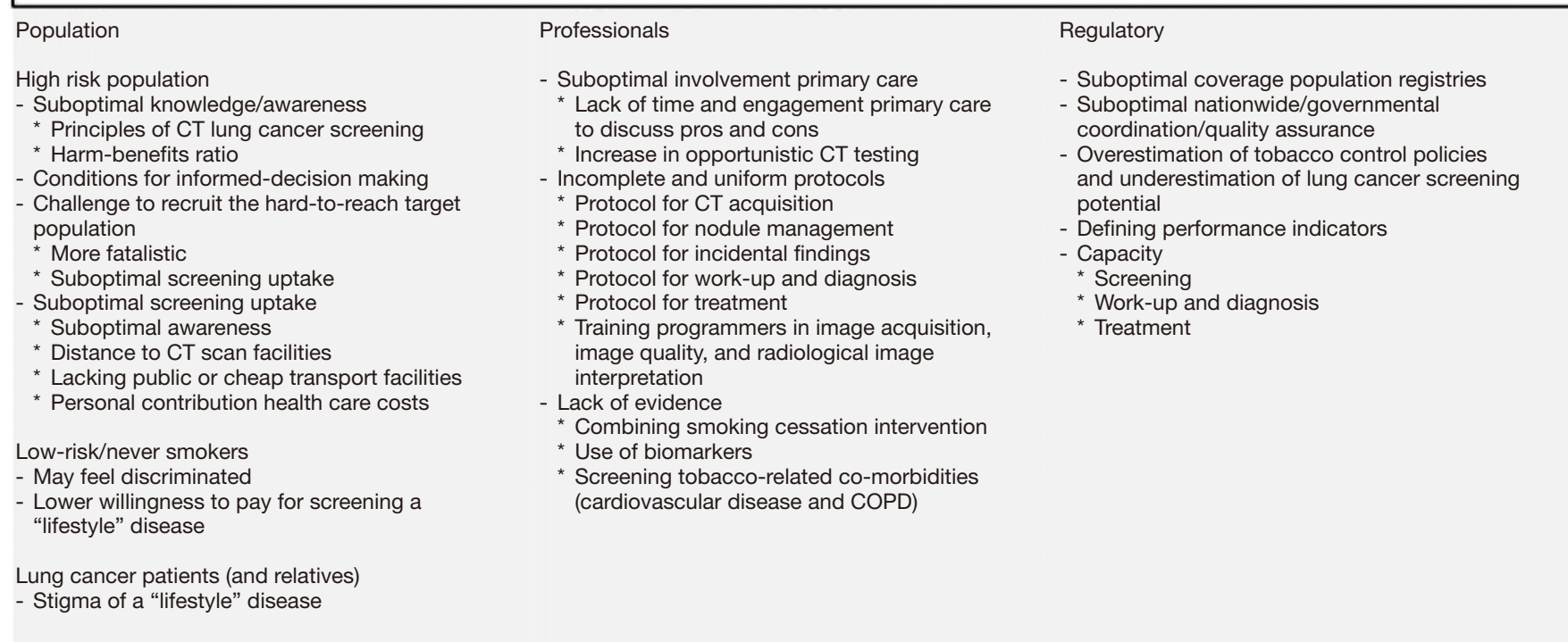

Figure 3 Potential barriers in the implementation of lung cancer screening.

with $1.02 \%$ for all screened participants (27). Another study indicated that, e.g., $44.6 \%$ of all first incidence screenings could have been skipped at the cost of a delayed diagnosis for only $9.8 \%$ of cancers (42).

The NELSON trial also found that the probability of a lung cancer diagnosis in the 2 years following the baseline CT-screen was lowest for participants with a negative (no abnormality or nodules $<50 \mathrm{~mm}^{3}$ ) baseline screening test result $(0.4 \%)$, and increased for a larger volume, diameter, or both, of the largest lung nodule up to a lung cancer probability of $25.7 \%$ for a volume of $1,000 \mathrm{~mm}^{3}$ or greater, or $31.6 \%$ for a diameter of $30 \mathrm{~mm}$ or greater (43). This result was supported by a risk prediction model for lung nodules, which showed promising performance in distinguishing between malignant and benign lung nodules (44). These results imply that information obtained from the baseline screening, as well as information from e.g., biomarkers, could be used to accurately personalise screening intervals based on an individual's risk, thereby improving the interventions for individuals. 


\section{Volume CT lung cancer screening and a 3-way test result}

NELSON is the first trial that shows that volume CT lung cancer screening of high-risk former and current smokers results in low referral rates $(2.3 \%)$, while retaining the substantial reductions in lung cancer mortality: $26 \%$ for men and $39-61 \%$ for women. Part of the strategy is the introduction of an indeterminate screening test result, that significantly decreases the number of test-positives and its subsequent follow-up procedures with all potential harms and costs associated with work-up procedures without affecting the favourable outcomes. Thereby, the reductions in lung cancer mortality were even more favourable as compared to the reduction found in the NLST for both genders.

Retrospective data analyses show that the cut-off for negative, indeterminate, and positive screening test result could be more optimal. Mainly based on the NELSON trial, new nodule management protocols based on volume and volume doubling time were published in the European Position Statement on Lung Cancer. Baseline thresholds for a negative screening test result was limited to $100 \mathrm{~mm}^{3}$, an indeterminate screening test result to $100-300 \mathrm{~mm}^{3}$ and a positive screening test result to $300 \mathrm{~mm}^{3}$ and above. After repeat CT scanning, a cut-off for the volume doubling time of 600 days indicates referral to the pulmonologist for further work-up procedures.

More stringent cut-offs for newly detected lung nodules are needed due to the increased probability of malignancy in these nodules: $<30 \mathrm{~mm}^{3}$ is classified as negative, $30-200 \mathrm{~mm}^{3}$ as indeterminate that requires a repeat CT scan, and $200 \mathrm{~mm}^{3}$ and above indicates direct referral to the pulmonologist $(45,46)$. So, separate nodule management protocols are needed for baseline and subsequent screening rounds. Current recommendations from the European Position Statement to (additional) use volumetry was adopted by guidelines of the British Thoracic Society, Fleischer society and Lung-RADS to classify lung nodules (47-49).

\section{Smoking cessation}

Lung cancer screening has been argued to be a teachable moment for smoking cessation services: screened participants having higher cessation rates than the general smoking population, showing screening could be used to motivate individuals to quit (50). Combining lung cancer screening with a smoking cessation programme could also substantially reduce lung cancer mortality, and other co-morbidities (51). Smoking cessation impacts a wide spectrum of tobacco related health problems, such as cardiovascular diseases and COPD (52). The CTexamination itself and the communication of the results of the examination should be investigated as opportunities to acknowledge the importance of smoking cessation, i.e., as "teachable moments", for both high and low intensity smokers (50,53). Many eligible participants will have one or more (pre-clinical) co-morbid conditions, due to their long-term smoking history. CT screening has been shown to be an excellent method to detect these smokingrelated comorbidities, which are common in the eligible population (54). Information, derived from the CT scan related to personalised risk for developing lung cancer, coronary heart disease (CHD) and emphysema, can be used as an incentive for people to adopt risk-reducing behaviour.

Unfortunately, there is still limited evidence on how to integrate (effective) smoking cessation services for both high- as well as low-risk smokers in a CT lung cancer screening context. Thereby, most intervention studies reported no or limited effect of the smoking cessation programme on smoking behaviour amongst participants $(50,53)$. Due to insufficient evidence so far, research is needed regarding the best type of (evidencebased) intervention, frequency, modality, or content of the communication in a population of smokers at high risk for developing lung cancer (55-61). In general, it seems that the more intensive the smoking cessation intervention is, the more personalised the communication would be, the higher its effectiveness will be. It is likely that those eligible for lung cancer screening have a (very) long-term smoking history, often with multiple quit attempts during their life, which highlights the complexity for behaviroual change for this specific population.

\section{Gender and sex differences}

While tobacco use was previously largely a male phenomenon, the gap in smoking prevalence between male and female adults is becoming smaller in many countries. Moreover, results of lung cancer screening trials indicate that females might benefit more from screening compared to men. The NLST reported a relative risk (RR) for dying from lung cancer of 0.92 (95\% CI: 0.8-1.08) in males, in contrast to a RR of 0.73 (95\% CI: 0.6-0.9) in females at 6 years of follow-up (62). The lung cancer mortality 
reduction in NELSON was 0.76 (95\% CI: $0.61-0.94$ ) for males and 0.67 (95\% CI: 0.38-1.14) for (the small subsample) females. In the Italian pooled analyses, the HR for lung cancer mortality was 3.51 (95\% CI: 1.50-8.21) for males as compared to females (63). The LUSI trial also confirms a gender difference in lung cancer mortality after screening: HR among males was 0.94 (95\% CI: 0.541.61 ) and among females 0.31 (95\% CI: 0.10-0.96) (12). Of interest is whether this different impact of lung cancer screening is sex-related (biological: e.g., histology, susceptibility, effect of treatment) and/or genderrelated (cultural, social, psychological and behavioural: e.g., smoking patterns, health seeking behaviour, willingness to participate, screening adherence, treatment acceptance) (64).

Model analyses indicate sex differences in the mean preclinical duration with longer durations in females (65), which consequently affect screening performance. Thereby, men are more likely to be diagnosed with the more aggressive lung tumours. This is also reflected by the fact that (screen-detected) lung cancer in men is less often in an early stage. As a result, curative treatment is less common in men compared to women. This all suggests that the optimal nodule management algorithm and/or screening interval might also differ per sex.

Possible suboptimal screening-from invitation to treatment-could lead to less favourable early detection and treatment outcomes. A recent review found that those with a lower social-economic status and women are less likely to be screened for lung cancer, even if they are at high risk (66). Attention should be paid to the underlying barriers and facilitators related to participating, especially since these populations are expected to benefit most from a population screening programme. Furthermore, health messages should also be tailored to both gender and SES, since it is well known that males and females are often motivated differently for continuing smoking or health behaviour change as a consequence of biological, psychological, social and cultural aspects. Men are, for example, more likely to be nicotine dependent, while women are more likely to be psychologically dependent. Women are more likely to make a quit attempt, although men are more likely to succeed. In lung cancer screening, gender differences can be expected during the recruitment process, the impact of receiving CT screening and the screening test result, in health seeking behaviour and health behavioural change (smoking cessation). So far, evidence on gender differences in lung cancer screening is lacking.

\section{Co-morbidity reducing strategies}

Due to the long-term tobacco exposure, those who are eligible for lung cancer screening are also more prone to develop other major tobacco-related diseases as chronic obstructive pulmonary disease (COPD) and coronary artery diseases, which have also high incidence and mortality rates. Screening for these so-called BIG-3 tobacco related diseases is feasible within the context of CT lung cancer screening. Although the health benefits based on population-based RCTs are unknown so far, it is expected that a combined approach in the early detection and treatment of these diseases would be beneficial in this high-risk population.

The coronary artery calcium (CAC) score is argued to be useful by presenting an individualized cumulative lifetime risk exposure of (un)known risk factors, independent of traditional risk factors, but strongly related to both non-lethal major adverse CVD events (such as myocardial infarction and stroke) and all-cause mortality, as shown by numerous studies (67-72). Based on the total amount of CAC (Agatston score) (73), CAC scoring provides important opportunities for personalized risk assessment to identify those who might benefit most from preventive treatment (74). Data from the large-scale RCTs, indicating that CAC screening for CHD will reduce CHD-related mortality and morbidity, are still lacking, but the outcomes of the only large-scale population-based randomized-controlled screening trial for cardiovascular diseases (ROBINSCA: Risk Or Benefit in Screening for CArdiovascular disease are being expected soon. Recent results showed that the early detection of a high risk for developing coronary heart disease by CT screening (CAC score) might reduce preventive treatment substantially $(75,76)$. This would imply that a significant reduction in potential overtreatment could be reduced by using the CAC score.

\section{Cost-effectiveness and healthcare resource capacity}

Many countries require health-care interventions to be cost-effective, before implementation can be considered. A number of studies have evaluated the cost-effectiveness of lung cancer screening in different countries, such as for the U.S., New-Zealand, Canada, Germany and Switzerland (29,30,77-79). These studies suggest that the cost-effectiveness of lung cancer screening is generally dependent on the invitation of high-risk individuals for 
screening and that the costs of the CT scans is one of the main drivers of the total costs of lung cancer programmes.

Aside from costs, healthcare resource capacity and the access to screening programmes need to be considered. Implementing a lung cancer screening program requires both CT scanner capacity, as well as the training of sufficient radiologists to evaluate the screens. An additional aspect to consider is the increased demand in surgical capacity due to screening (80-82). While late-stage lung cancers are generally treated through radiotherapy and chemotherapy, early-stage lung cancers are often treated through surgical resection. Given that lung cancer screening will lead to an increased detection of early-stage cancers, an increased demand for surgical capacity should be expected. Indeed, modelling studies for the U.S. have suggested that an adherence rate of $50 \%$ would require a $37 \%$ increase in surgical capacity. Therefore, health-care resource capacity should be taken in to consideration for implementing lung cancer screening. Gradual implementation strategies with modelling informing resource allocation should be considered.

Given that the selection of high-risk individuals is essential for cost-effective implementation of lung cancer screening, higher risk-thresholds than previously applied in pilot studies could ensure cost-effectiveness. For example, a $\mathrm{PLCO}_{\mathrm{m} 2012} 6$-year risk of $2.5 \%$ may be more appropriate for cost-effective implementation of lung cancer screening in Europe. Furthermore, higher risk-thresholds may be considered in the implementation phase to meet resource requirements; similarly to the implementation phase of the Dutch colorectal cancer screening program (82).

In addition, even with a sufficient screening capacity, access to these lung cancer screening programmes remains crucial, especially since lung cancer incidence is elevated in the more deprived groups. For the U.S., lung cancer screening is covered by Centers for Medicare and Medicaid Services (CMS) and private insurances, but for people in underserved communities, the underinsurance or even the lack of insurance for screening and follow-up for screendetected abnormalities are enormous barriers to screening uptake, although smoking and lung cancer is more prevalent among these individuals (83).

\section{European CT lung cancer implementation trial}

Currently, several countries started with pilot lung cancer screening programmes. These include for instance the UK centres; The Lung Screen Uptake Trial, The SUMMIT study (London), Early detection of lung disease pilot (Manchester); UK Lung Screen (UKLS) pilot; but also, the lung cancer screening pilots in Poland and Croatia (17,84-87).

However, implementing a new cancer screening programme is a major task, with many stakeholders and many possible facilitators but also barriers and obstacles. Figure 2 and 3 summarize the main challenges and important potential barriers. There are good reasons to believe that further optimisation of lung cancer screening programs will reduce harms and maintain or enhance benefit for eligible European citizens, whilst significantly reducing health care costs. The above-mentioned uncertainties discussed in this review require large-scale implementation trial(s) throughout Europe to address these key issues.

4-IN-THE-LUNG-RUN (acronym for: Towards INdividually tailored INvitations, screening INtervals and INtegrated co-morbidity reducing strategies in lung cancer screening) is the first multi-centred implementation trial on volume CT lung cancer screening amongst 24,000 males and females, at high risk for developing lung cancer, across five European countries, started in January 2020 (88).

The overall objective of the 4-IN-THE-LUNG-RUN project is to develop and implement the optimal, highquality CT lung cancer screening programme for high-risk populations (88).

Therefore, the primary aim is to assess the relative safety (comparable detection of lung cancer stage I-II) of a personalised risk-based (often) less intensive screening regimen (annual screening versus biennial screening in baseline test negatives) on the basis of a combination of (I) health risk factors, (II) baseline CT scan result and possibly ultimately (III) biomarker outcomes amongst individuals at high risk for developing lung cancer. Furthermore, aim of the trail is to compare population based (general) recruitment approach with the more individually (gender specific) tailored approaches. Finally, the trial aims to design and integrate effective personalized smoking cessation and co-morbidity reducing services within a CT lung cancer screening context, in which additional information from the CT scan on tobacco-related co-morbidities (CAC, COPD) is integrated.

Through providing answers to the remaining questions, many EU citizens will swiftly benefit from this highquality screening technology, others will face less harms than previously anticipated and health care costs will be substantially reduced. 


\section{4-IN-THE-LUNG-RUN consortium}

Erasmus MC-University Medical Centre Rotterdam, The Netherlands: Carlijn van der Aalst, Kevin Ten Haaf, Dana Moldovanu, Harry J. de Koning; University of Nottingham, United Kingdom: David Baldwin, Emma O’Dowd, Rachael Murray; iDNA Research BV, The Netherlands: Matthijs Oudkerk; German Cancer Research Centre, Germany: Verena Katzke, Rudolf Kaaks; Catalan Institute of Oncology, Spain: Josep Borras, Josep A Espinàs; University Clinic Essen, Germany: Nicoleas Becker, Clemens Aigner; Institute Goustave Roussy, France: Corinne Balleyguier, David Planchard; University College London, United Kingdom: Sam Janes; Instituto Nazionale Tumori, Italy: Gabriella Sozzi, Ugo Pastorino, Chiara Bovolenta.

\section{Acknowledgments}

Funding: This review was funded by EU-Horizon 2020 grant (4-IN-THE-LUNG-RUN; lung cancer screening implementation trial; grant number 848294). The funder had no role in study design, data collection and analysis, decision to publish, or preparation of this paper.

\section{Footnote}

Provenance and Peer Review: This article was commissioned by the Guest Editor (Witold Rzyman) for the series "Implementation of CT-based screening of lung cancer" published in Translational Lung Cancer Research. The article has undergone external peer review.

Conflicts of Interest: All authors have completed the ICMJE uniform disclosure form (available at http://dx. doi. org/10. 21037/tlcr-20-985). The series "Implementation of CT-based screening of lung cancer" was commissioned by the editorial office without any funding or sponsorship. CM van der Aalst reports grants from European Commission - Horizon 2020, during the conduct of the study; grants and non-financial support from Central European Lung Cancer Conference, grants from NIH/National Cancer Institute, outside the submitted work. KTH reports grants from European Union (Horizon 2020), during the conduct of the study; grants from University of Zurich, Switzerland, non-financial support from International Association for the Study of Lung Cancer, non-financial support from International Association for the Study of Lung Cancer, grants from Cancer Research UK, non-financial support from Russian Society of Clinical Oncology, non-financial support and other from Biomedical Research in Endstage And Obstructive Lung Disease Hannover (BREATH), grants from NIH/National Cancer Institute, outside the submitted work. HJ de Koning reports grants from European Commission - Horizon 2020, during the conduct of the study; personal fees from speakers fee, other from NHS England, grants from NIH/National Cancer Institute, outside the submitted work. The authors have no other conflicts of interest to declare.

Ethical Statement: The authors are accountable for all aspects of the work in ensuring that questions related to the accuracy or integrity of any part of the work are appropriately investigated and resolved.

Open Access Statement: This is an Open Access article distributed in accordance with the Creative Commons Attribution-NonCommercial-NoDerivs 4.0 International License (CC BY-NC-ND 4.0), which permits the noncommercial replication and distribution of the article with the strict proviso that no changes or edits are made and the original work is properly cited (including links to both the formal publication through the relevant DOI and the license). See: https://creativecommons.org/licenses/by-nc-nd/4.0/.

\section{References}

1. Ferlay J, Colombet M, Soerjomataram I, et al. Cancer incidence and mortality patterns in Europe: Estimates for 40 countries and 25 major cancers in 2018. Eur J Cancer 2018;103:356-87.

2. Siegel RL, Miller KD, Jemal A. Cancer statistics, 2016. CA Cancer J Clin 2016;66:7-30.

3. Services. US Department of Health and Human Services. The Health Consequences of Smoking-50 Years of Progress: A Report of the Surgeon General. Atlanta: US Department for Health and Human Services, Centers for Disease Control and Prevention, National Center for Chronic Disease Prevention and Health Promotion, Office on Smoking and Health, 2014.

4. National Lung Screening Trial Research Team, Aberle DR, Adams AM, et al. Reduced lung-cancer mortality with low-dose computed tomographic screening. N Engl J Med 2011;365:395-409.

5. de Koning HJ, Meza R, Plevritis SK, et al. Benefits and harms of computed tomography lung cancer screening strategies: a comparative modeling study for the U.S. 
Preventive Services Task Force. Ann Intern Med 2014;160:311-20.

6. Humphrey LL, Deffebach M, Pappas M, et al. Screening for lung cancer with low-dose computed tomography: a systematic review to update the US Preventive services task force recommendation. Ann Intern Med 2013;159:411-20.

7. de Koning HJ, van der Aalst CM, ten Haaf K, et al. PL02.05 - Effects of Volume CT Lung Cancer Screening: Mortality Results of the NELSON RandomisedControlled Population Based Trial. Toronto, Canada: 19th World Conference on Lung Cancer, 2018.

8. Infante M, Cavuto S, Lutman FR, et al. Long-Term Follow-up Results of the DANTE Trial, a Randomized Study of Lung Cancer Screening with Spiral Computed Tomography. Am J Respir Crit Care Med 2015;191:1166-75.

9. Wille MM, Dirksen A, Ashraf H, et al. Results of the Randomized Danish Lung Cancer Screening Trial with Focus on High-Risk Profiling. Am J Respir Crit Care Med 2016;193:542-51.

10. Paci E, Puliti D, Lopes Pegna A, et al. Mortality, survival and incidence rates in the ITALUNG randomised lung cancer screening trial. Thorax 2017;72:825-31.

11. Pastorino U, Silva M, Sestini S, et al. Prolonged lung cancer screening reduced 10-year mortality in the MILD trial: new confirmation of lung cancer screening efficacy. Ann Oncol 2019;30:1162-9.

12. Becker N, Motsch E, Trotter A, et al. Lung cancer mortality reduction by LDCT screening-Results from the randomized German LUSI trial. Int J Cancer 2020;146:1503-13.

13. Jeon J, Holford TR, Levy DT, et al. Smoking and Lung Cancer Mortality in the United States From 2015 to 2065: A Comparative Modeling Approach. Ann Intern Med 2018;169:684-93.

14. Lönnberg S, Šekerija M, Malila N, et al. Chapter 4: Cancer screening: policy recommendations on governance, organization and evaluation of cancer screening. Ljubljana: European Guide on Quality Improvement in Comprehensive Cancer Control, 2017.

15. Jonas D, Reuland DS, Reddy SM, et al. Screening for Lung Cancer With Low-Dose Computed Tomography: An Evidence Review for the U.S. Preventive Services Task Force. Evidence Synthesis Number 198, 2020.

16. McRonald FE, Yadegarfar G, Baldwin DR, et al. The UK Lung Screen (UKLS): demographic profile of first 88,897 approaches provides recommendations for population screening. Cancer Prev Res (Phila) 2014;7:362-71.
17. Field JK, Duffy SW, Baldwin DR, et al. The UK Lung Cancer Screening Trial: a pilot randomised controlled trial of low-dose computed tomography screening for the early detection of lung cancer. Health Technol Assess 2016;20:1-146.

18. Field JK, Duffy SW, Baldwin DR, et al. UK Lung Cancer RCT Pilot Screening Trial: baseline findings from the screening arm provide evidence for the potential implementation of lung cancer screening. Thorax 2016;71:161-70.

19. Yousaf-Khan U, Horeweg N, van der Aalst H, et al. Baseline characteristics and mortality outcomes of NELSON control group participants and eligible nonresponders. J Thorac Oncol 2015;10:747-53.

20. See K, Manser R, Park ER, et al. The impact of perceived risk, screening eligibility and worry on preference for lung cancer screening: A cross-sectional survey. ERJ Open Res 2020;6:00158-2019.

21. Leishman J, Fagerlin A, Lowery J, et al. Predictors of eligible patients' agreeing to lung cancer screening with low-dose computed tomography: A multilevel retrospective cohort study. J Gen Intern Med 2019;34:S320.

22. Ali N, Lifford KJ, Carter B, et al. Barriers to uptake among high-risk individuals declining participation in lung cancer screening: a mixed methods analysis of the UK Lung Cancer Screening (UKLS) trial. BMJ Open 2015;5:e008254.

23. Rennert L, Zhang L, Lumsden B, et al. Factors influencing lung cancer screening completion following participation in shared decision-making: A retrospective study in a U.S. academic health system. Cancer Treat Res Commun 2020;24:100198.

24. Lillie SE, Fu SS, Fabbrini AE, et al. What factors do patients consider most important in making lung cancer screening decisions? Findings from a demonstration project conducted in the Veterans Health Administration. Lung Cancer 2017;104:38-44.

25. Quaife SL, Ruparel M, Dickson JL, et al. Lung Screen Uptake Trial (LSUT): Randomized Controlled Clinical Trial Testing Targeted Invitation Materials. Am J Respir Crit Care Med 2020;201:965-75.

26. Dickson J, Quaife S, Horst C, et al. The SUMMIT study: invitation strategy and screening uptake of the first 36,680 invited. Lung Cancer 2020;139:S5.

27. Patz EF Jr, Greco E, Gatsonis C, et al. Lung cancer incidence and mortality in National Lung Screening Trial participants who underwent low-dose CT prevalence screening: a retrospective cohort analysis of a randomised, 
multicentre, diagnostic screening trial. Lancet Oncol 2016;17:590-9.

28. ten Haaf K, Jeon J, Tammemägi MC, et al. Risk prediction models for selection of lung cancer screening candidates: A retrospective validation study. PLoS Med 2017; 14:e1002277.

29. Ten Haaf K, Tammemagi MC, Bondy SJ, et al. Performance and Cost-Effectiveness of Computed Tomography Lung Cancer Screening Scenarios in a Population-Based Setting: A Microsimulation Modeling Analysis in Ontario, Canada. PLoS Med 2017; 14:e1002225.

30. Tomonaga Y, Ten Haaf K, Frauenfelder T, et al. Costeffectiveness of low-dose CT screening for lung cancer in a European country with high prevalence of smoking-A modelling study. Lung Cancer 2018;121:61-9.

31. Oudkerk M, Devaraj A, Vliegenthart R, et al. European position statement on lung cancer screening. Lancet Oncol 2017;18:e754-66.

32. Li ZY, Luo L, Hu YH, et al. Lung cancer screening: a systematic review of clinical practice guidelines. Int J Clin Pract 2016;70:20-30.

33. Tammemägi MC, Church TR, Hocking WG, et al. Evaluation of the lung cancer risks at which to screen everand never-smokers: screening rules applied to the PLCO and NLST cohorts. PLoS Med 2014;11:e1001764.

34. Ten Haaf K, Bastani M, Cao P, et al. A Comparative Modeling Analysis of Risk-Based Lung Cancer Screening Strategies. J Natl Cancer Inst 2020;112:466-79.

35. Aldrich MC, Mercaldo SF, Sandler KL, et al. Evaluation of USPSTF Lung Cancer Screening Guidelines Among African American Adult Smokers. JAMA Oncol 2019;5:1318-24.

36. Han SS, Chow E, Ten Haaf K, et al. Disparities of National Lung Cancer Screening Guidelines in the US Population. J Natl Cancer Inst 2020;112:1136-42.

37. Pasquinelli MM, Tammemägi MC, Kovitz KL, et al. Risk Prediction Model Versus United States Preventive Services Task Force Lung Cancer Screening Eligibility Criteria: Reducing Race Disparities. J Thorac Oncol 2020;15:1738-47.

38. Hüsing A, Kaaks R. Risk prediction models versus simplified selection criteria to determine eligibility for lung cancer screening: an analysis of German federalwide survey and incidence data. Eur J Epidemiol 2020;35:899-912.

39. Tammemagi MC, Schmidt H, Martel S, et al. Participant selection for lung cancer screening by risk modelling (the
Pan-Canadian Early Detection of Lung Cancer [PanCan] study): a single-arm, prospective study. Lancet Oncol 2017;18:1523-31.

40. Lim KP, Marshall H, Tammemägi M, et al. Protocol and Rationale for the International Lung Screening Trial. Ann Am Thorac Soc 2020;17:503-12.

41. Lebrett MB, Balata H, Evison M, et al. Analysis of lung cancer risk model (PLCO(M2012) and LLP(v2)) performance in a community-based lung cancer screening programme. Thorax 2020;75:661-8.

42. Schreuder A, Schaefer-Prokop CM, Scholten ET, et al. Lung cancer risk to personalise annual and biennial followup computed tomography screening. Thorax 2018. [Epub ahead of print].

43. Horeweg N, van Rosmalen J, Heuvelmans MA, et al. Lung cancer probability in patients with CT-detected pulmonary nodules: a prespecified analysis of data from the NELSON trial of low-dose CT screening. Lancet Oncol 2014;15:1332-41.

44. McWilliams A, Tammemagi MC, Mayo JR, et al. Probability of cancer in pulmonary nodules detected on first screening CT. N Engl J Med 2013;369:910-9.

45. Walter JE, Heuvelmans MA, de Bock GH, et al.

Relationship between the number of new nodules and lung cancer probability in incidence screening rounds of CT lung cancer screening: The NELSON study. Lung Cancer 2018;125:103-8.

46. Walter JE, Heuvelmans MA, de Jong PA, et al. Occurrence and lung cancer probability of new solid nodules at incidence screening with low-dose CT: analysis of data from the randomised, controlled NELSON trial. Lancet Oncol 2016;17:907-16.

47. Callister ME, Baldwin DR, Akram AR, et al. British Thoracic Society guidelines for the investigation and management of pulmonary nodules. Thorax 2015;70 Suppl 2:ii1-54.

48. MacMahon H, Naidich DP, Goo JM, et al. Guidelines for Management of Incidental Pulmonary Nodules Detected on CT Images: From the Fleischner Society 2017. Radiology 2017;284:228-43.

49. Radiology ACo. Lung CT Screening Reporting \& Data System (Lung-RADS); Lung-RADS® Version 1.1 Assessment Categories Release date: 2019. Available online: https://www.acr.org/-/media/ACR/Files/RADS/ Lung-RADS/LungRADSAssessmentCategoriesv1-1.pdf

50. Slatore CG, Baumann C, Pappas M, et al. Smoking behaviors among patients receiving computed tomography for lung cancer screening. Systematic review in support of 
the U.S. preventive services task force. Ann Am Thorac Soc 2014;11:619-27.

51. Tanner NT, Kanodra NM, Gebregziabher M, et al. The Association between Smoking Abstinence and Mortality in the National Lung Screening Trial. Am J Respir Crit Care Med 2016;193:534-41.

52. Tramontano AC, Sheehan DF, McMahon PM, et al. Evaluating the impacts of screening and smoking cessation programmes on lung cancer in a high-burden region of the USA: a simulation modelling study. BMJ Open 2016;6:e010227.

53. Pineiro B, Simmons VN, Palmer AM, et al. Smoking cessation interventions within the context of LowDose Computed Tomography lung cancer screening: A systematic review. Lung Cancer 2016;98:91-8.

54. Mets OM, Vliegenthart R, Gondrie MJ, et al. Lung cancer screening CT-based prediction of cardiovascular events. JACC Cardiovasc Imaging 2013;6:899-907.

55. Pua BB, Dou E, O'Connor K, et al. Integrating smoking cessation into lung cancer screening programs. Clin Imaging 2016;40:302-6.

56. Marshall HM, Courtney DA, Passmore LH, et al. Brief Tailored Smoking Cessation Counseling in a Lung Cancer Screening Population is Feasible: A Pilot Randomized Controlled Trial. Nicotine Tob Res 2016;18:1665-9.

57. Bade M, Bahr V, Brandt U, et al. Effect of smoking cessation counseling within a randomised study on early detection of lung cancer in Germany. J Cancer Res Clin Oncol 2016;142:959-68.

58. Pozzi P, Munarini E, Bravi F, et al. A combined smoking cessation intervention within a lung cancer screening trial: a pilot observational study. Tumori 2015;101:306-11.

59. Ashraf H, Saghir Z, Dirksen A, et al. Smoking habits in the randomised Danish Lung Cancer Screening Trial with low-dose CT: final results after a 5-year screening programme. Thorax 2014;69:574-9.

60. van der Aalst CM, de Koning HJ, van den Bergh KA, et al. The effectiveness of a computer-tailored smoking cessation intervention for participants in lung cancer screening: a randomised controlled trial. Lung Cancer 2012;76:204-10.

61. Garcia-Gomez L, Hernandez-Perez A, Noe-Diaz V, et al. Smoking Cessation Treatments: Current Psychological and Pharmacological Options. Rev Invest Clin 2019;71:7-16.

62. National Lung Screening Trial Research Team. Lung Cancer Incidence and Mortality with Extended Followup in the National Lung Screening Trial. J Thorac Oncol 2019;14:1732-42.
63. Infante M, Sestini S, Galeone C, et al. Lung cancer screening with low-dose spiral computed tomography: evidence from a pooled analysis of two Italian randomized trials. Eur J Cancer Prev 2017;26:324-9.

64. Fishman J, Wick, J., \& Koenig, B. The Use of "Sex" and "Gender" to Define and Characterize Meaningful Differences between Men and Women: Agenda for Research on Women's Health for the 21st Century. Bethesda: NIH Publication, 1999.

65. Ten Haaf K, van Rosmalen J, de Koning HJ. Lung cancer detectability by test, histology, stage, and gender: estimates from the NLST and the PLCO trials. Cancer Epidemiol Biomarkers Prev 2015;24:154-61.

66. Schutte S, Dietrich D, Montet X, et al. Participation in lung cancer screening programs: are there gender and social differences? A systematic review. Public Health Rev 2018;39:23.

67. Detrano R, Guerci AD, Carr JJ, et al. Coronary calcium as a predictor of coronary events in four racial or ethnic groups. N Engl J Med 2008;358:1336-45.

68. McClelland RL, Bild DE, Burke GL, et al. Alcohol and coronary artery calcium prevalence, incidence, and progression: results from the Multi-Ethnic Study of Atherosclerosis (MESA). Am J Clin Nutr 2008;88:1593-601.

69. Hoffmann U, Massaro JM, D'Agostino RB Sr, et al. Cardiovascular Event Prediction and Risk Reclassification by Coronary, Aortic, and Valvular Calcification in the Framingham Heart Study. J Am Heart Assoc 2016;5:e003144.

70. Erbel R, Budoff M. Improvement of cardiovascular risk prediction using coronary imaging: subclinical atherosclerosis: the memory of lifetime risk factor exposure. Eur Heart J 2012;33:1201-13.

71. Hecht HS. Coronary artery calcium scanning: past, present, and future. JACC Cardiovasc Imaging 2015;8:579-96.

72. Kianoush S, Al Rifai M, Cainzos-Achirica M, et al. An Update on the Utility of Coronary Artery Calcium Scoring for Coronary Heart Disease and Cardiovascular Disease Risk Prediction. Curr Atheroscler Rep 2016;18:13.

73. Agatston AS, Janowitz WR, Hildner FJ, et al. Quantification of coronary artery calcium using ultrafast computed tomography. J Am Coll Cardiol 1990;15:827-32.

74. Elias-Smale SE, Proenca RV, Koller MT, et al. Coronary calcium score improves classification of coronary heart disease risk in the elderly: the Rotterdam study. J Am Coll Cardiol 2010;56:1407-14. 
75. van der Aalst CM, Denissen SJAM, Vonder M, et al. Screening for cardiovascular disease risk using traditional risk factor assessment or coronary artery calcium scoring: the ROBINSCA trial. Eur Heart J Cardiovasc Imaging 2020;21:1216-24.

76. van der Aalst CM, Vonder M, Gratama JW, et al. Risk or Benefit in Screening for Cardiovascular Disease (ROBINSCA): The Rationale and Study Design of a Population-Based Randomized-Controlled Screening Trial for Cardiovascular Disease. J Clin Trials 2019;9:1.

77. Treskova M, Aumann I, Golpon H, et al. Trade-off between benefits, harms and economic efficiency of lowdose CT lung cancer screening: a microsimulation analysis of nodule management strategies in a population-based setting. BMC Med 2017;15:162.

78. Jaine R, Kvizhinadze G, Nair N, et al. Cost-effectiveness of a low-dose computed tomography screening programme for lung cancer in New Zealand. Lung Cancer 2020;144:99-106.

79. Criss SD, Cao P, Bastani M, et al. Cost-Effectiveness Analysis of Lung Cancer Screening in the United States: A Comparative Modeling Study. Ann Intern Med 2019;171:796-804.

80. Blom EF, Ten Haaf K, Arenberg DA, et al. Disparities in Receiving Guideline-Concordant Treatment for Lung Cancer in the United States. Ann Am Thorac Soc 2020;17:186-94.

81. Blom EF, Ten Haaf K, Arenberg DA, et al. Treatment capacity required for full-scale implementation of lung cancer screening in the United States. Cancer 2019;125:2039-48.

82. van Hees F, Zauber AG, van Veldhuizen H, et al. The

Cite this article as: van der Aalst CM, ten Haaf K, de Koning HJ; for the 4-IN-THE-LUNG-RUN Consortium. Implementation of lung cancer screening: what are the main issues? Transl Lung Cancer Res 2021;10(2):1050-1063. doi: $10.21037 /$ tlcr-20-985 value of models in informing resource allocation in colorectal cancer screening: the case of The Netherlands. Gut 2015;64:1985-97.

83. Wang GX, Baggett TP, Pandharipande PV, et al. Barriers to Lung Cancer Screening Engagement from the Patient and Provider Perspective. Radiology 2019;290:278-87.

84. Quaife SL, Ruparel M, Beeken RJ, et al. The Lung Screen Uptake Trial (LSUT): protocol for a randomised controlled demonstration lung cancer screening pilot testing a targeted invitation strategy for high risk and 'hard-to-reach' patients. BMC Cancer 2016;16:281.

85. University College London Hospitals NHS Foundation Trust (UCLH). Largest ever UK lung cancer screening study seeks to detect lung cancer early amongst at-risk Londoners and supports development of a new blood test for early detection of cancer 2019. Available online: https://www.uclh.nhs.uk/News/Pages/UCLHandUCLtoe mbarkuponthelargesteverlungcancerscreeningprojectinthe UK.aspx

86. Crosbie PA, Balata H, Evison M, et al. Second round results from the Manchester 'Lung Health Check' community-based targeted lung cancer screening pilot. Thorax 2019;74:700-4.

87. Rzyman W, Szurowska E, Adamek M. Implementation of lung cancer screening at the national level: Polish example. Transl Lung Cancer Res 2019;8:S95-105.

88. 4-IN THE LUNG RUN: towards INdividually tailored INvitations, screening INtervals, and INtegrated comorbidity reducing strategies in lung cancer screening. European Commission. Available online: https://cordis. europa.eu/project/id/848294 